\title{
TEORIA DA COCULPABILIDADE: BUSCA DA IGUALDADE MATERIAL COMO AFIRMAÇÃO DA DEMOCRACIA
}

\author{
Nestor Eduardo Araruna Santiago* \\ Déborah Sousa Braga**
}

SUMÁRIO: Introdução; 1.1 A Democracia como Governo do Povo; 2 Igualdade e Liberdade na Democracia; 3 Democracia e Desigualdades Sociais; 4 Teoria da Coculpabilidade; 5 Considerações Finais; Referências.

RESUMO: A democracia é fundada na liberdade e na igualdade não só formal, mas também material. Consiste no governo do povo, diretamente ou por meio de seus representantes, para alcançar o bem comum. Assim, o Estado deve atuar, observando os direitos e as garantias individuais, reconhecendo a liberdade dos seus cidadãos (direitos negativos), mas também assumindo a sua responsabilidade em fornecer a eles os serviços básicos como saúde, educação e moradia. Diante da omissão estatal na prestação de tais condições mínimas de desenvolvimento à grande parcela da população, em evidente afronta à dignidade da pessoa humana, e da constatação de que boa parte das pessoas presas já tinha sido excluída socialmente, antes mesmo de ser encarcerada, por ter sido preterida pelas políticas públicas, surge a teoria da coculpabilidade. Para essa teoria, as circunstâncias sociais de cada acusado devem ser consideradas para compensar a sua responsabilidade com a do Estado e da sociedade por serem estes omissos na formação desses indivíduos, podendo atenuar a pena ou deixar de aplicá-la no caso concreto. Por meio de estudo bibliográfico, puro, dedutivo e qualitativo, serão apresentadas a evolução da ideia de democracia, a importância das políticas públicas que assegurem condições dignas de sobrevivência e, ao final, a exposição da teoria da coculpabilidade como busca da igualdade material e, portanto, meio de afirmação da democracia.

PALAVRAS-CHAVE: Democracia; Coculpabilidade; Igualdade Material; Direito Penal.

\section{THE THEORY OF CO-BLAME: MATERIAL EQUALITY AS A DEMOCRATIC STANCE}

ABSTRACT: Democracy is based on formal and material freedom and equality. It is the government of the people, directly or through representatives, for the

\footnotetext{
Doutor em Direito; Docente Titular do Programa de Pós-Graduação em Direito Constitucional e da Graduação em Direito da Universidade de Fortaleza (UNIFOR), Brasil; E-mail: nestoreasantiago@gmail.com

${ }^{*}$ Mestre em Direito Constitucional pelo Programa de Pós-Graduação em Direito Constitucional pela Universidade de Fortaleza (UNIFOR), Brasil.
} 
common good. The State should take care of individual rights and guarantees by acknowledging the freedom of its citizens (negative rights) but taking responsibility in offering basic services such as health, education and home, In case the State fails in such minimum developmental conditions to all, in contempt of the dignity of the human person, and due to the fact that many convicts had been socially excluded before being imprisoned, the theory of co-blame may be discussed. The social circumstances of each convict should be taken into account to compensate responsibility of the State and society since the latter have failed in the formation of the individuals. Punishment may be mitigated or not meted out. A deductive and qualitative bibliographical analysis will reveal the evolution of the idea of democracy and the importance that public policies to warrant survival conditions. The theory of co-blame will be discussed as a search for material equality and a stand for democracy.

KEY WORDS: Democracy; Co-blame; Material Equality; Penal Law.

\section{TEORÍA DE LA CO-CULPABILIDAD: BUSQUEDA DE LA IGUALDAD MATERIAL COMO AFIRMACIÓN DE LA DEMOCRACIA}

RESUMEN: La democracia es fundada en la libertad y en la igualdad no solo del punto de vista formal, sino también material. Consiste en el gobierno del pueblo, directamente o por medio de sus representantes, para alcanzar el bien común. Así, el Estado debe actuar, observando los derechos y las garantías individuales, reconociendo la libertad de sus ciudadanos (derechos negativos), pero también asumiendo su responsabilidad en fornecer a ellos servicios básicos de salud, educación y vivienda. Delante de la omisión estatal en la prestación de tales condiciones mínimas de desarrollo a gran parte de la población, en afronta a la dignidad de la persona humana, y de la constatación de que parte de las personas encarceladas ya había sido excluida socialmente anteriormente por falta de acceso a las políticas públicas, es que surge la teoría de la co-culpabilidad. Para esa teoría, las circunstancias sociales de cada acusado deben ser consideradas considerando las responsabilidades del Estado y de la sociedad por ser omisos en la formación de estos individuos, lo que puede asegurar la reducción de la pena o dejar de aplicarla concretamente. Por medio de un estudio bibliográfico, puro, deductivo y cualitativo, será presentada la evolución de la idea de democracia, la importancia de las políticas públicas que puedan asegurar las condiciones mínimas de supervivencia y, al fin, será expuesta la teoría de la co-culpabilidad como búsqueda de la igualdad material y, por lo tanto, medio de afirmación de la democracia.

PALABRAS-CLAVE: Democracia; Co-culpabilidad; Igualdad Material; Derecho Penal. 


\section{INTRODUÇÃO}

A democracia é um valor construído ao longo da história da humanidade e consiste no poder do povo com intuito de atingir o bem de todos. Atenas traz o modelo inicial de democracia de participação direta, mas restrita aos homens atenienses livres e maiores de 20 anos ${ }^{1}$.

Apesar das críticas dirigidas a Platão e Aristóteles, que defendiam que o povo não seria capaz de tomar as melhores decisões para o destino da pólis e que o ideal seria o governo dos escolhidos, como os filósofos ${ }^{2}$, a ideia de democracia atravessou os séculos e hoje possui conotação positiva e mais abrangente, por envolver todos os membros da sociedade, baseada nos conceitos de liberdade e igualdade.

Essa igualdade basilar da democracia não é aquela meramente formal e sim a material, que busca tratar os iguais igualmente e os desiguais desigualmente, na justa medida de suas diferenças. Acrescente-se ainda que o Estado democrático de Direito é caracterizado pela soberania, pela divisão de poderes, pelo império da lei e pela observância aos direitos e às garantias fundamentais: nesse contexto, o direito penal deve ter aplicação restrita, em observância aos direitos e às garantias fundamentais do indivíduo e somente quando as demais áreas do direito não foram capazes de resolver determinada situação fática (ultima ratio).

Some-se a isso que o Estado deve observar tais direitos não apenas negativamente, permitindo o exercício da liberdade pelos cidadãos, mas também reconhecendo os direitos positivos, consistentes na prestação de serviços básicos que assegurem a formação e o desenvolvimento do cidadão.

Assim, diante da omissão estatal no oferecimento de deveres constitucionais como saúde, educação e moradia e do aumento de delitos patrimoniais com indicação de que as circunstâncias sociais podem ter contribuído para a prática deles, surge no direito penal a teoria da coculpabilidade, que analisa a parcela de responsabilidade da sociedade e do Estado em delitos cometidos por pessoas socialmente excluídas que, normalmente, ocupam os estratos sociais mais baixos da sociedade.

No presente artigo, serão analisadas a evolução da ideia de democracia, a importância da igualdade material como elemento fundamental daquela e a teoria

${ }^{1}$ HELD, David. Modelos de democracia. Tradução Alexandre Sobreira Martins. Belo Horizonte: Paideia, 1987, p. 21.

${ }^{2}$ GOYARD-FABRE, Simone. O que é democracia?: a genealogia filosófica de uma grande aventura humana. São Paulo: Martins Fontes, 2003, p. 28. 
da coculpabilidade com análise acerca da sua possibilidade no ordenamento jurídico brasileiro. Tem-se como base o método dedutivo, para, a partir dele, utilizar-se uma pesquisa básica quanto à natureza, qualitativa quanto à abordagem, exploratória quanto aos objetivos e bibliográfica quanto à técnica.

\subsection{A DEMOCRACIA COMO GOVERNO DO POVO}

A ideia clássica de democracia remonta a Atenas, no século V a.C., quando era exercida diretamente pelos cidadãos que eram parcela da população ateniense de homens livres e maiores de 20 (vinte) anos. Além disso, a realização do ateniense consistia em participar ativamente das escolhas da polis, sendo a liberdade vinculada a essa atuação nas decisões da cidade e não com a conotação de direito individual atual ${ }^{3}$.

A noção de governo pelo povo recebeu severas críticas dos filósofos, como Platão e Aristóteles, que entendiam que o povo não teria a sabedoria necessária para se autogovernar e que somente as pessoas que detivessem o conhecimento, como os próprios filósofos, estariam aptas a gerir a cidade. Além disso, a falta de uma liderança levaria à desobediência por parte de todos, não sendo viável um governo nesses moldes.

Nesse sentido, David Held ressalta o entendimento de Platão sobre o governo democrático de que os líderes em uma democracia sempre adotariam medidas populares para a sua manutenção no poder, não tendo a coragem necessária para tomar decisões difíceis, mas necessárias, que pudessem desagradar a maioria do povo $^{4}$.

Goyard-Fabre frisa a ambivalência que envolveu a democracia: de um lado, a escolha de um governo que buscasse a igualdade de todos, de outro, o receio de que resultasse em anarquia, consistindo na negação da política5.

Apesar das críticas e da alegada contradição interna, a democracia, após sua consolidação durante os séculos, atualmente possui significado mais amplo ao incluir todo o povo, e não mais só os homens, passando a adotar o regime representativo em razão da inviabilidade da manifestação direta acerca das questões da cidade diante do aumento populacional e da complexidade das temáticas a serem deliberadas.

\footnotetext{
3 HELD, op. cit., 1987, p. 17.

${ }^{4}$ HELD, op. cit., 1987, p. 29.

5 GOYARD-FABRE, op. cit., 2003, p. 61.
} 
Além disso, a democracia assumiu conotação positiva, sendo certo que todos os governos e Estados perceberam a conveniência de se autodenominarem democratas, ainda que não seja efetivamente o interesse do povo que norteie as decisões do Estado.

Ressalte-se que a busca pela democratização das instituições é relevante como maneira de se efetivar a participação popular nas decisões políticas, mas se deve ter o cuidado para se evitar o uso indiscriminado do termo democracia com interesse em legitimar, inclusive, regimes em que o poder não pertence ao povo ou que são nitidamente antidemocráticos.

O Estado democrático de Direito assume, então, a função de instrumento para alcançar o bem de todos e deve ser regido pelo império da lei e pela observância aos direitos e às garantias fundamentais ${ }^{6}$.

\section{IGUALDADE E LIBERDADE NA DEMOCRACIA}

Primeiramente, cabe esclarecer que a democracia não se instala em um Estado apenas com a sua implementação na ordem política, sendo necessário corrigir as desigualdades sociais. Nesse sentido, Atílio A. Boron entende que a democracia é incompatível com as diferenças sociais extremas, sendo indispensável para a efetivação da cidadania que as reivindicações políticas e sociais sejam observadas ${ }^{7}$.

Boron defende que a democracia, como o governo do povo, exige a coexistência da liberdade e da igualdade. Isso porque assegurar a liberdade para todos como único fundamento da democracia não é suficiente, pois as extremas desigualdades na formação e no desenvolvimento do ser humano podem influenciar diretamente no seu discernimento. Portanto, não basta que cada cidadão seja livre para decidir os rumos de sua vida: é necessário que tenha condições reais de fazer tais escolhas. ${ }^{8} \mathrm{Na}$ democracia, portanto, faz-se necessária a igualdade material entre os cidadãos que consiste no tratamento igual aos que sejam iguais e desigual aos desiguais, na exata medida de suas diferenças, cabendo ao Estado promover políticas

${ }^{6}$ BARCELLOS, Ana Paula de. Neoconstitucionalismo, direitos fundamentais e controle das políticas públicas, 2006, p.42

BORON, Atílio A. Estado, capitalismo e democracia na América Latina. São Paulo: Paz e Terra, 1994, p. 13.

${ }^{8}$ BORON, op.cit., p.13; PINTO, Simone Matos Rios. O princípio da co-culpabilidade. Disponível em: < http:// ejef.tjmg.jus.br/home/files/publicacoes/artigos/0162008.pdf>. Acesso em: 18 nov 2013, p.2. 
sociais mínimas que assegurem a dignidade dos cidadãos. ${ }^{9}$

De fato, para o exercício da liberdade é primordial que cada indivíduo tenha condições mínimas de existência e, ao se omitir em favorecer prestações afirmativas, o Estado democrático atinge a dignidade de cada cidadão e acaba por se autodestruir, fazendo com que as diferenças sociais, se alimentadas, corroam a ideia da verdadeira democracia.

A cidadania não é entendida apenas sob o aspecto eleitoral. Ela assume conotação ampla, possuindo conceito positivo no sentido de incluir também ações estatais que efetivem os direitos sociais ${ }^{10}$. Desta feita, a omissão do Estado no tocante à realização das políticas públicas tem proporcionado grandes distorções sociais, em detrimento dos direitos e das garantias fundamentais, do exercício das liberdades, do tratamento igualitário e, em última análise, da própria democracia.

A situação de desigualdade social, sofrida pela população brasileira, deixa evidenciado que as políticas públicas básicas (saúde, educação e moradia dignas, por exemplo) não têm sido efetivas, como se depreende da análise a seguir.

\section{DEMOCRACIA E DESIGUALDADES SOCIAIS}

Analisando-se os dados do InfoPen ${ }^{11}$, que registra indicadores gerais e preliminares sobre a população penitenciária do país, ao considerar o grau de escolaridade apenas dos detentos do Estado do Ceará (dados referentes a 78\% dos encarcerados), $7 \%$ são de analfabetos, 25\%, de alfabetizados, mas sem frequentar cursos regulares e $45 \%$ possuem ensino fundamental incompleto. Além disso, $9 \%$ possuem ensino fundamental completo, 6\%, o ensino médio incompleto, 6\%, o ensino médio completo e $2 \%$ possuem pelo menos o ensino superior incompleto.

Assim, constata-se pela análise desses números que, em regra, o número de presos diminui conforme aumenta o grau de instrução. Esclareça-se que não se quer afirmar de maneira simplista que somente o analfabeto ou pessoa de pouca instrução comete crimes. Mas se quer ressaltar que pode haver relação entre a

9 SILVA, João Carlos Carvalho da. Princípio da co-culpabilidade e sua implementação no ordenamento jurídico brasileiro. 2009, p. 5.

${ }^{10}$ CARVALHO, José Murilo de. Cidadania no Brasil: o longo caminho. 3. ed. Rio de Janeiro: Civilização Brasileira, 2001, p.219.

${ }^{11}$ BRASIL. Ministério da Justiça. Levantamento Nacional de Informações Penitenciárias - Infopen. 2014. Disponível em: < http://www.justica.gov.br/seus-direitos/politica-penal/relatorio-depen-versao-web.pdf $>$. Acesso em: 29 jul. 2015, p.59. 
ausência de formação educacional e, portanto, a falta de perspectivas profissionais e a prática de delitos. Ou seja, a falha na prestação estatal de serviços mínimos, como a educação básica para todos, tem como consequência a marginalização de parte da sociedade, que passa a viver sem expectativas de se tornar economicamente ativa ${ }^{12}$.

Isso porque, numa sociedade de consumo e extremamente competitiva, é evidente a dificuldade de se sobreviver sem uma educação formal mínima que habilite o cidadão minimamente para o mercado de trabalho.

Assim, está-se diante do aumento dos números de delitos, muitos deles de natureza patrimonial e que parecem refletir a realidade desigual, vivida na sociedade. Acredita-se que é cada vez mais difícil, numa sociedade de consumo, que alguém possa viver sem instrução e sem qualquer perspectiva de trabalho, normalmente decorrente dessa mesma falta de instrução. Nesse caso, pergunta-se se o Estado pode ser responsabilizado, ainda que de forma solidária, por sua omissão na prestação da educação, saúde e moradia, como elementos mínimos, para grande parte da população.

Esta é uma análise superficial de apenas um dos direitos sociais que é a educação. No entanto, não resta dúvida de que o direito penal tem se ocupado em controlar pessoas que já tinham sido excluídas socialmente e previamente ao cometimento do delito.

Ressalte-se que o direito penal se destina a reprimir condutas sociais indesejadas, mas não pode ser utilizado de maneira ampla para suprir omissão anterior estatal na prestação de políticas públicas. $\mathrm{O}$ Estado não deve substituir a ausência da implementação de políticas públicas por meio do direito penal ${ }^{13}$.

Nesse sentido, Guimarães afirma não ser justo que o indivíduo tenha o primeiro contato com o Estado no âmbito do direito penal, por ter permanecido à margem da sociedade ao não terem sido efetivados os direitos fundamentais. $\mathrm{E}$ acrescenta que a punição justa pressupóe o mesmo ponto de partida para todos os cidadãos. ${ }^{14}$

Acrescente-se que no Estado democrático de Direito, o direito penal é regido pelo princípio da intervenção mínima, devendo ser a ultima ratio, priorizando a liberdade de seus cidadãos, prevendo apenas as condutas de tamanha gravidade e

\footnotetext{
${ }_{12}$ PINTO, Simone Matos Rios, op.cit., p. 4

${ }^{13}$ GUIMARÃES, Cláudio Alberto Gabriel. A culpabilidade compartilhada como princípio mitigador da ausência de efetivação dos direitos humanos fundamentais. Revista de Informação Legislativa, Brasília, v. 46, n. 184, out./dez. 2009, p. 56-57

${ }^{14}$ GUIMARÃES, Cláudio Alberto Gabriel, op.cit., p.61
} 
que não podem ser resolvidas nas outras esferas do direito.

No entanto, no Estado brasileiro, tem-se assistido à omissão estatal no tocante às políticas públicas que assegurem o mínimo existencial digno para considerável parcela da população e o aumento da prática de crimes patrimoniais por pessoas cada vez mais jovens ${ }^{15}$.

Com a criminalidade crescente, não raras vezes surgem ideias de aumento de penas, redução da maioridade penal, endurecimento no cumprimento de penas e construção de novos presídios: não há qualquer preocupação em se assegurar condições dignas de encarceramento, esquecendo-se de que os apenados retornarão ao convívio social, do qual já tinham sido excluídos antes mesmo de serem encarcerados. Moura ressalta que o medo em razão da insegurança pública suscita o fortalecimento da repressão, alterações legislativas e até mesmo a autotutela por parte de membros da sociedade - o "fazer justiça pelas próprias mãos"16.

No entanto não resta dúvida de que as saídas utilizadas para o rigor penal são equivocadas porque não resolvem o problema verdadeiramente, tais como a redução da maioridade penal e a produção legislativa desenfreada, apenas procuram remediar as suas consequências. Isso porque a ampliação do direito penal não será capaz de reduzir a criminalidade decorrente da ausência de políticas públicas mínimas que deveriam ter sido prestadas pelo Estado, bem como pela ausência de política criminal que integre direito penal, direito processual penal e as criminologias.

Cabe ao Estado e à sociedade perceber que questões ligadas à segurança pública não se resolvem apenas com repressão, mas - e principalmente - com políticas públicas integradas que assegurem o desenvolvimento digno dos cidadãos como maneira de incluí-los socialmente e proporcionar oportunidade de viverem de forma lícita e economicamente ativa.

\section{TEORIA DA COCULPABILIDADE}

Zaffaroni e Pierangeli (2009, p.521) afirmam que a culpabilidade pressupõe a possibilidade de compreensão da antijuridicidade da conduta e a capacidade

\footnotetext{
${ }^{15}$ PINTO, Simone Matos Rios, op.cit., p.4

${ }^{16}$ MOURA, João Carlos da Cunha. O direito penal na era do déficit das instituições democráticas. In: CARVALHO, Gisele Mendes de; DEODATO, Felipe Augusto Forte de Negreiros; ARAÚJO NETO, Félix. Criminologias e Política Criminal II. In: CONGRESSO NACIONAL DO CONPEDI, 23., 2014. Anais... Florianópolis: CONPEDI, 2014, p. 478.
} 
de autodeterminar-se ${ }^{17}$. É, então, o senso de reprovação criado pela conduta. Na doutrina brasileira, também Fragoso ${ }^{18}$, Bruno ${ }^{19}$, Greco $^{20}$, Bitencourt ${ }^{21}$ e Brandão ${ }^{22}$ integram a doutrina que adota a teoria tripartite, incluindo a culpabilidade como elemento para caracterização do crime que seria fato típico, antijurídico e culpável.

No entanto registre-se que, após a reforma penal de 1984 , Damásio ${ }^{23}$ e Mirabete e Fabbrini ${ }^{24}$ defenderam que o ordenamento jurídico passava a adotar a teoria bipartite, sendo exigíveis apenas a tipicidade e a antijuridicidade para caracterizar o crime e que a culpabilidade seria apenas condição para imposição da pena. Muñoz Conde defende ainda que, para se caracterizar o delito, além de o fato ser típico, antijurídico, culpável, deveria ser também punível, o que criaria um quarto elemento para a configuração do crime, qual seja, a punibilidade ${ }^{25}$.

Cabe considerar que, embora o Código Penal (CP), ao se referir à culpabilidade em algumas situações, utilize expressões relacionadas à aplicação da pena, na verdade, a culpabilidade continua sendo elemento para caracterização do crime e que não só a culpabilidade, como também a tipicidade e a antijuridicidade também são pressupostos para aplicação da pena, incidindo diretamente sobre a aplicação da pena-base, nos termos do CP, art. $59^{26}$.

Assim, a culpabilidade está intimamente relacionada com o princípio da individualização da pena que rege a atuação do Poder Legislativo, ao fixar os limites mínimo e máximo da pena em abstrato, e a atuação do Poder Judiciário ao definir a pena em concreto na sentença e ao estabelecer a forma de cumpri-la no momento da execução penal.

Acrescente-se que o juiz fixará a pena privativa de liberdade, o regime inicial de seu cumprimento e verificará a possibilidade de sua substituição por outra cabível, considerando as circunstâncias judiciais previstas no art. 59 do CP que são a culpabilidade, os antecedentes criminais, a conduta social, a personalidade do

\footnotetext{
${ }_{17}$ ZAFFARONI, Eugenio Raul; PIERANGELI, José Henrique. Manual de direito penal brasileiro: parte geral - v. I. 7. ed. São Paulo: Revista dos Tribunais, 2009, p. 521.

${ }^{18}$ FRAGOSO, Heleno Cláudio. Lições de direito penal: parte geral. 16. ed. Rio de Janeiro: Forense, 2003, p. 178.

${ }^{19}$ BRUNO, Aníbal. Direito penal: parte geral. 2.ed. Rio de Janeiro: Forense, 1959, p. 275.

${ }^{20}$ GRECO, Rogério. Curso de direito penal: parte geral. 6.ed. Rio de Janeiro: Impetus, 2013, p. 147.

${ }^{21}$ BITENCOURT, Cezar Roberto. Tratado de direito penal: parte geral. 16. ed. São Paulo: Saraiva, 2011, p. 253.

${ }^{22}$ BRANDÃO, Cláudio. Curso de direito penal: parte geral. Rio de Janeiro: Forense, 2008, p. 118-119.

${ }^{23}$ JESUS, Damásio Evangelista de. Direito penal: parte geral. 27. ed. rev e atual. São Paulo: Saraiva, 2003, p. 154.

${ }^{24}$ MIRABETE, Júlio Fabbrini e FABBRINI, Renato N. Manual de direito penal: parte geral. 24.ed. rev e atual. São Paulo: Atlas, 2007, p. 84-85.

${ }^{25}$ MUÑOZ CONDE, Francisco. Teoria geral do direito penal. Porto Alegre: Fabris, 1988, p. 5.

${ }^{26}$ GRECO, Rogério, loc. cit.
} 
agente, os motivos e as consequências do crime e comportamento da vítima. Percebese, portanto, que o juiz deve analisar elementos acerca do fato e da gravidade do delito, bem como acerca das circunstâncias pessoais do autor, tendo sido adotada pelo $\mathrm{CP}$ a tese de que a culpabilidade seria mista ${ }^{27}$.

Percebe-se que as características pessoais são consideradas por ocasião da fixação da pena e os defensores da teoria da coculpabilidade ${ }^{28}$ afirmam que as circunstâncias sociais e as oportunidades de cada pessoa também precisam ser observadas no momento de se averiguar a culpabilidade de alguém acusado da prática de delitos.

Essa teoria, também conhecida como culpabilidade pela vulnerabilidade ${ }^{29}$, possui influência da teoria filosófica da natureza das coisas, iniciada desde a Antiguidade e desenvolvida por São Tomás de Aquino que defendia que, ainda que tenha sido cometido o mesmo delito, as punições não podem nem devem ser iguais para todas as pessoas, devendo ser aplicadas as penas, considerando-se a natureza das coisas, ou seja, as particularidades do caso concreto ${ }^{30}$.

O fundamento é, portanto, na ideia de que a responsabilidade das pessoas está diretamente relacionada com as suas características pessoais que decorrem de vários fatores, dentre eles, as circunstâncias sociais em que estão inseridas.

João Carlos Carvalho da Silva defende que o ordenamento jurídico brasileiro prevê a culpabilidade de forma mista, nos termos do art. 59 do CP, ao considerar as circunstâncias do fato criminoso, mas também as condições pessoais do infrator. Além disso, ressalta a parcela de culpa do Estado quando o crime cometido decorre da ausência de condições dignas de sobrevivência ${ }^{31}$. Assim, acolher a teoria da coculpabilidade seria compensar a culpa do cidadão perante a omissão estatal e da sociedade anterior no fornecimento de políticas públicas mínimas. No entender de Batista, trata-se de alinhar a responsabilidade do acusado com a do Estado: "em certa medida, a co-culpabilidade faz sentar no banco dos réus, ao lado dos mesmos réus, a sociedade que os produziu"32.

\footnotetext{
${ }^{27}$ SILVA, João Carlos Carvalho da. Princípio da co-culpabilidade e sua implementação no ordenamento jurídico brasileiro. 2009. Disponível em: <http://mpto.mp.br/cint/cesaf/arqs/040209043401.pdf>. Acesso em 18 nov. 2013.

${ }^{28}$ SILVA, op. cit.,GUIMARÃES, op .cit, PINTO, op.cit.

${ }^{29}$ ARAÚJO, Jader Máximo. O princípio da coculpabilidade como causa atenuante inominada. De Jure - Revista Jurídica do Ministério Público do Estado de Minas Gerais, Belo Horizonte, jan./jun. 2013, v.12, n.20, p. 136.

${ }^{30}$ GUIMARÃES, op. cit., p. 60.

${ }^{31}$ SILVA, op. cit.

${ }^{32}$ BATISTA, Nilo. Introdução crítica ao direito penal brasileiro. 8. ed. Rio de Janeiro: Revan, 2002, p. 105.
} 
Verifica-se que a teoria da coculpabilidade é compatível com uma das finalidades do Estado brasileiro, que é reduzir desigualdades regionais e sociais e decorreria dos princípios da igualdade e da individualização da pena, que define ser direito do cidadão ser punido na exata medida do que fez. De forma mais refinada, cuida-se de uma depuração do próprio conceito de culpabilidade como elemento da teoria tripartite do crime.

Araújo ressalta que, com a lei n. 10.792/2003, que alterou o rito do interrogatório, a teoria da coculpabilidade teria sido acolhida pelo ordenamento jurídico de maneira expressa ${ }^{33}$. Isso porque, em razão da referida lei, o $\S 1^{\circ}$ do art. 187 do Código de Processo Penal (CPP) passou a prever que o interrogatório será realizado em duas partes, sendo a primeira acerca das condições pessoais do acusado, inclusive aquelas relativas às oportunidades sociais, e, no segundo momento, seria perquirido sobre a acusação que lhe é feita.

Além disso, os defensores da culpabilidade pela vulnerabilidade ${ }^{34}$ entendem $^{-}$ que, antes mesmo da referida alteração no CPP, ela já teria aplicação no ordenamento jurídico brasileiro por meio da previsão de atenuante inominada no art.66 do CP. Acrescente-se ainda que a lei n. 9.605/1998, que trata dos crimes ambientais, já previa no art.14 que o baixo grau de instrução ou escolaridade do agente é causa atenuante da pena, reconhecendo a influência de questões sociais no momento da individualização da pena.

Registre-se que, no atual projeto de lei n. 236/2012 que pretende reformar a parte geral do CP, o art. 75 dispõe sobre as circunstâncias judicias e exclui a conduta social e a personalidade do agente, atualmente previstas no art. 59 do CP e para as quais dificilmente há elementos nas ações penais para avaliá-las. No entanto não há referência à observância da realidade social em que estaria inserido o sentenciado por ocasião da fixação da pena, distanciando-se da teoria da coculpabilidade.

Araújo ressalta que a teoria da coculpabilidade reconhece a realidade brasileira de grandes desigualdades sociais e que a liberdade de escolha do indivíduo pode ser limitada pelas circunstâncias sociais em que está inserido ${ }^{35}$. No entanto salienta que nem todas as pessoas que vivem de maneira miserável serão necessariamente infratoras; apenas defende que, nesses casos em que o grau de autodeterminação é reduzido, seria quase impossível exigir um comportamento

\footnotetext{
33 ARAÚJO, op. cit., p. 146.

${ }^{34}$ Por todos, ver PINTO, op.cit., p.7

${ }^{35}$ ARAÚJO, op. cit., p. 139.
} 
socialmente adequado e conforme o ordenamento jurídico ${ }^{36}$.

Silva e Giacoia ${ }^{37}$ afirmam que as causas do crime são difusas, não se podendo entender sua prática apenas como decorrência da precariedade econômica, mas ressaltam que pessoas desprovidas de poder econômico chegam mais facilmente ao sistema penal e têm suas garantias fundamentais desrespeitadas.

Nesse sentido, os dados colhidos pelo Censo Penitenciário do Ceará 2014 confirmam que "quanto menor a escolaridade, maiores são os números de crimes contra a pessoa e contra o patrimônio" 38 .

No entanto não se pode presumir que todos aqueles que vivem em situação econômica desfavorável sejam voltados a cometer crimes, numa visão determinista que é incompatível com a defesa da dignidade da pessoa humana e que pode ser refutada pela análise na realidade em que muitas pessoas que viveram em situação financeiramente difícil conseguiram superar as privações iniciais e vivem dignamente. Não se pode deixar de reconhecer que tais pessoas necessitaram de esforço extra se comparado com outros que nasceram em família ajustada e com melhores condições financeiras. Assim, segundo Gomes, seria tolerável que o juiz, ao graduar a pena in concreto, levasse em consideração a situação social do agente, por ser manifestação do princípio da proporcionalidade no direito pena ${ }^{39}$.

Os defensores da teoria da coculpabilidade defendem que aquele que sempre esteve à margem da sociedade, não tendo o Estado efetivado os direitos e as garantias fundamentais, não poderia ser punido da mesma forma do que aquele que teve a liberdade plena de escolha em razão das oportunidades que lhe foram oferecidas.

Nesse sentido, Guimarães ${ }^{40}$ defende que,

para que Estado possa punir de forma justa e legítima, necessário se faz que todos os cidadãos tenham tido, no ponto de partida, as mesmas oportunidades. Ratificamos, o cidadão não pode ter como primeiro contato com o Estado o banco dos réus em um processo

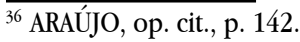

${ }^{37}$ SILVA, Lucas Soares e; GIACOIA, Gilberto. Exclusão social e criminalização do excluído: uma reflexão sobre a seletividade do sistema penal brasileiro. In: SANTIAGO, Nestor Eduardo Araruna; BORGES, Paulo César Corrêa; PEREIRA, Cláudio José Langroiva. Direito Penal e Criminologia: XXII Congresso Nacional do Conpedi - Uninove. Florianópolis: FUNJAB, 2013, p. 446.

${ }^{38}$ CEARÁ. Censo Penitenciário do Ceará. 2014. Disponível em <http://www.sejus.ce.gov.br/index.php/component/content/article/58-cidadania-interna/1827-censo-penitenciario > . Acesso em 11 mar. 2015

${ }^{39}$ GOMES, Mariângela Gama de Magalhães. O princípio da proporcionalidade no direito penal. São Paulo: Revista dos Tribunais, 2003, p. 206.

${ }^{40}$ GUIMARÃES, op.cit. p. 60.
} 
criminal.

Não se trata de pregar a impunidade ou de justificar a conduta do acusado e sim de compensar de alguma forma as desigualdades sociais vividas. Ressalte-se que a desigualdade na formação de cada indivíduo pode ser essencial para suas escolhas futuras. A ausência de igualdade material limita o exercício da liberdade.

Acerca do receio da impunidade, tal argumento seria mais adequado aos crimes conhecidos por "colarinho branco" do que aqueles cometidos por pessoas desfavorecidas economicamente. Estas certamente consideram que dificilmente serão presas ou surpreendidas na primeira infração, mas parecem estar motivadas mais pela total falta de perspectivas do que pela certeza de não ser presas.

Guimarães defende que as privações sociais poderiam ser causas impeditivas de punibilidade, conforme o caso concreto, sustentando que seria necessário definir parâmetros para a sua aplicação como: quando se tratar de crimes praticados sem violência contra a vítima, agente for primário e for detectada a sua vulnerabilidade extrema. Nesses casos, defende a não aplicação da pena e o encaminhamento para programas públicos de inclusão social. Registre-se, no entanto, que tal entendimento é polêmico porque a coculpabilidade absoluta é vista como favorecimento à impunidade ou anarquia social ${ }^{41}$.

A coculpabilidade limitada pode ser reconhecida como atenuante genérica, prevista no art. 66 do CP, sendo maneira de individualizar a pena, considerando-se as oportunidades sociais do apenado. Desta feita, para Busato, a coculpabilidade interferiria na análise da potencial consciência da ilicitude e na exigibilidade de conduta diversa, pois "aquele cuja liberdade é limitada pela estrutura social em que vive não pode ter um mesmo nível de internalização de valores contidos na norma, nem pode ser submetido a igual nível de exigência para que atue conforme aquela, em determinados casos concretos" ${ }^{\prime 2}$.

Apesar de a culpabilidade pela vulnerabilidade ser consoante aos valores constitucionais da igualdade material, da individualização da pena e até mesmo da humanidade das punições, ainda enfrenta resistência para o reconhecimento nos tribunais.

O Tribunal de Justiça do Rio Grande do Sul, reconhecido por seus posicionamentos de vanguarda em alguns casos, não acolhe a teoria da coculpabilidade, como se depreende da ementa da relatoria do desembargador José

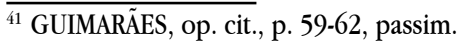

${ }^{42}$ BUSATO, Paulo César. Direito penal: parte geral. São Paulo: Atlas, 2013, p. 554. 
Conrado Kurtz de Souza que entende que "não há falar em aplicação de atenuante genérica com esteio na denominada coculpabilidade do Estado, porquanto se trata de tese frágil e de enorme subjetividade, esboroando-se já na constatação de que o crime alcança, sem distinção, camadas sociais economicamente privilegiadas". 43

Além disso, a desembargadora Isabel de Borba Lucas, do mesmo tribunal, não acolheu a tesa da coculpabilidade porque ela não possui "previsão legal e porque a hipótese ventilada não se trata de circunstância relevante a ponto de provocar a redução da pena pelo art. 66 do CP. Não se pode responsabilizar a sociedade pela ausência de oportunidades ao indivíduo, bem como a culpabilidade não decorre da pobreza, pois presente o crime em todas as camadas sociais". ${ }^{44}$

Ressalte-se ainda ementa de decisão da relatoria da ministra Maria Thereza de Assis Moura, do Superior Tribunal de Justiça, que claramente afasta tal teoria ao proferir que "O Superior Tribunal de Justiça não tem admitido a aplicação da teoria da coculpabilidade do Estado como justificativa para a prática de delitos". ${ }^{45}$

Registre-se também o entendimento da ministra Laurita Vaz no sentido de que "a teoria da coculpabilidade não pode ser erigida à condição de verdadeiro prêmio para agentes que não assumem a sua responsabilidade social e fazem da criminalidade um meio de vida", acrescentando ainda que, por se tratar de decisão em sede de habeas corpus seria inviável a apreciação dos fatos para se investigar se a omissão estatal na prestação de direitos positivos teria contribuído de alguma forma para a prática do crime. ${ }^{46}$

Percebe-se que, embora já possua aceitação doutrinária, a teoria da culpabilidade pela vulnerabilidade ainda não tem sido acolhida pelo Superior Tribunal de Justiça, tribunal responsável pela uniformização de jurisprudência dos tribunais estaduais e federais no Brasil, ainda estando associada à ideia de impunidade.

\footnotetext{
${ }_{43}$ RIO GRANDE DO SUL. Tribunal de Justiça do Rio Grande do Sul. Apelação Crime 70055372189, Rel. José Conrado Kurtz de Souza, sétima câmara criminal, julgado em 24/10/2013. Diário de Justiça eletrônico, Porto Alegre, RS, 31 out. 2013.

${ }^{44}$ RIO GRANDE DO SUL. Tribunal de Justiça do Rio Grande do Sul. Apelação Crime 70052317104, Rel. Isabel de Borba Lus, oitava câmara criminal, julgado em 16/10/2013. Diário de Justiça eletrônico, Porto Alegre, RS, 21 nov. 2013.

${ }^{45}$ BRASIL. Superior Tribunal de Justiça. HC 187.132/MG. Rel. Ministra Maria Thereza de Assis Moura, sexta turma, julgado em 05/02/2013, Diário de Justiça eletrônico, Brasília, DF, 18 fev.2013.

${ }^{46}$ BRASIL. Superior Tribunal de Justiça. HC 191.622/TO. Rel. Ministra Laurita Vaz, quinta turma, julgado em 05/02/2013, Diário de Justiça eletrônico, Brasília, DF, 15 fev.2013.
} 


\section{CONSIDERAÇÕES FINAIS}

Não há democracia com mera igualdade formal, sendo necessário promover a igualdade material entre os cidadãos. É dever do Estado democrático de Direito implementar políticas públicas que promovam a formação e o desenvolvimento pleno do indivíduo.

A omissão do Estado e da sociedade tem provocado enormes desigualdades sociais, com reflexos na ordem pública com o acréscimo da prática de delitos, em especial de natureza patrimonial.

Em razão disso, o Estado social tem sido substituído pelo Estado penal nas muitas situações em que o indivíduo tem vivido à margem da sociedade antes mesmo de ser preso, acusado pela prática do delito.

A teoria da coculpabilidade propõe compensar a culpa do infrator com a do Estado e da sociedade, seja atenuando a pena, nos termos do art. 59 e do art. 66 do CP, seja como causa impeditiva de punibilidade, de forma criteriosa e apenas quando comprovadas a extrema vulnerabilidade e a ausência de periculosidade do infrator.

Não se trata de promover a impunidade, incentivar a prática de crimes ou mesmo a injustiça, mas de reconhecer que o Estado é responsável por implementar políticas públicas que assegurem a vida digna para os seus cidadãos, não podendo se omitir nesse tocante e exigir desses preteridos na mesma medida aplicada para aqueles para os quais ofereceu oportunidade de pleno desenvolvimento.

\section{REFERÊNCIAS}

ARAÚJO, Jader Máximo. O princípio da coculpabilidade como causa atenuante inominada. De Jure - Revista Jurídica do Ministério Público do Estado de Minas Gerais, Belo Horizonte, v.12, n.20, p.107-152, jan./jun. 2013.

BARCELLOS, Ana Paula de. Neoconstitucionalismo, direitos fundamentais e controle das políticas públicas. In: SARMENTO, Daniel, GALDINO, Flávio (Org.). Direitos fundamentais: estudos em homenagem ao professor Ricardo Lobo Torres. Rio de Janeiro: Renovar, 2006, p.31-60. 
BATISTA, Nilo. Introdução crítica ao direito penal brasileiro. 8. ed. Rio de Janeiro: Revan, 2002.

BITENCOURT, Cezar Roberto. Tratado de direito penal: parte geral. 16. ed. São Paulo: Saraiva, 2011.

BORON, Atílio A. Estado, capitalismo e democracia na América Latina. São Paulo: Paz e Terra, 1994.

BRANDÃO, Cláudio. Curso de direito penal: parte geral. Rio de Janeiro: Forense, 2008.

BRASIL. Constituição (1988). Constituição da República Federativa da Brasil. Disponível em: <http://www.planalto.gov.br/ccivil_03/constituicao/constituicaocompilado.htm > . Acesso em: 10 jan. 2015.

BRASIL. Decreto-Lei n. 2.848, de 7 de dezembro de 1940. Código Penal. Disponível em: < http://www.planalto.gov.br/ccivil_03/decreto-lei/del2848.htm>. Acesso em: 10 jan. 2015.

BRASIL. Decreto-Lei n. 3.689, de 3 de outubro de 1941. Código de Processo Penal. Disponível em: < http://www.planalto.gov.br/ccivil_03/decreto-lei/Del3689. htm >. Acesso em: 10 jan. 2015.

BRASIL. Lei n. 10.792, de 01 de dezembro de 2003. Altera a Lei n.7.210, de 11 de junho de 1984 - Lei de Execução Penal e o Decreto-Lei n. 3.689, de 3 de outubro de 1941 - Código de Processo Penal e dá outras providências. Disponível em: <http:// www.planalto.gov.br/ccivil_03/leis/2003/L10.792.htm > Acesso em: 10 jan. 2015.

BRASIL. Lei n. 9.605, de 12 de fevereiro de 1998. Dispõe sobre as sanções penais e administrativas derivadas de condutas e atividades lesivas ao meio ambiente, e dá outras providências. Disponível em: < http://www.planalto.gov.br/ccivil_03/LEIS/ L9605.htm>. Acesso em: 10 jan. 2015.

BRASIL. Ministério da Justiça. Levantamento Nacional de Informações Penitenciárias - Infopen. 2014. Disponível em: < http://www.justica.gov.br/seus-direitos/ politica-penal/relatorio-depen-versao-web.pdf > . Acesso em: 29 jul. 2015. 
BRASIL. Senado Federal. Projeto de Lei do Senado 236/2012. Reforma o Código Penal brasileiro. Disponível em: < http://www.senado.gov.br/atividade/materia/ Consulta.asp?Tipo_Cons $=6 \&$ orderby $=0 \&$ Flag $=1 \& R A D \_T I P=$ OUTROS\&str_tipo $=$ PLS\&txt_num $=236 \&$ txt_ano $=2012>$. Acesso em: 20 jul 2015.

BRASIL. Superior Tribunal de Justiça. HC 187.132/MG. Rel. Ministra Maria Thereza de Assis Moura, sexta turma, julgado em 05/02/2013. Diário de Justiça eletrônico, Brasília, DF, 18 fev.2013.

BRASIL. Superior Tribunal de Justiça. HC 191.622/TO. Rel. Ministra Laurita Vaz, quinta turma, julgado em 05/02/2013, Diário de Justiça eletrônico, Brasília, DF, 15 fev. 2013.

BRUNO, Aníbal. Direito penal: parte geral. 2.ed. Rio de Janeiro: Forense, 1959.

BUSATO, Paulo César. Direito penal: parte geral. São Paulo: Atlas, 2013.

CARVALHO, José Murilo de. Cidadania no Brasil: o longo caminho. 3. ed. Rio de Janeiro: Civilização Brasileira, 2001

CEARÁ. Censo Penitenciário do Ceará. 2014. Disponível em: < http://www.sejus. ce.gov.br/index.php/component/content/article/58-cidadania-interna/1827-censo -penitenciario >. Acesso em: 11 mar. 2015.

FRAGOSO, Heleno Cláudio. Lições de direito penal: parte geral. 16. ed. Rio de Janeiro: Forense, 2003.

GOMES, Mariângela Gama de Magalhães. O princípio da proporcionalidade no direito penal. São Paulo: Revista dos Tribunais, 2003.

GOYARD-FABRE, Simone. O que é democracia?: a genealogia filosófica de uma grande aventura humana. São Paulo: Martins Fontes, 2003.

GRECO, Rogério. Curso de direito penal: parte geral. 6.ed. Rio de Janeiro: Impetus, 2013.

GUIMARÃES, Cláudio Alberto Gabriel. A culpabilidade compartilhada como princípio 
mitigador da ausência de efetivação dos direitos humanos fundamentais. Revista de informação legislativa, Brasília, v. 46, n. 184, p. 55-65, out./dez. 2009.

HELD, David. Modelos de democracia. Tradução Alexandre Sobreira Martins. Belo Horizonte: Paideia, 1987.

JESUS, Damásio Evangelista de. Direito penal: parte geral. 27. ed. rev e atual. São Paulo: Saraiva, 2003.

MIRABETE, Júlio Fabbrini e FABBRINI, Renato N. Manual de direito penal: parte geral. 24. ed. rev e atual. São Paulo: Atlas, 2007.

MOURA, João Carlos da Cunha. O direito penal na era do déficit das instituições democráticas. In: CARVALHO, Gisele Mendes de; DEODATO, Felipe Augusto Forte de Negreiros; ARAÚJO NETO, Félix. Criminologias e Política Criminal II. In: CONGRESSO NACIONAL DO CONPEDI UFPB, 23., 2014. Anais eletrônicos... Florianópolis: CONPEDI, 2014, p. 468-486. Disponível em: < http://www.publicadireito.com.br/ artigos/?cod=ce6907d94233d611 > . Acesso em: 01 jul. 2015.

MUÑOZ CONDE, Francisco. Teoria geral do direito penal. Tradução Juarez Távora e Luiz Régis Prado. Porto Alegre: Fabris, 1988.

PINTO, Simone Matos Rios. O princípio da co-culpabilidade. Disponível em $<$ http://ejef.tjmg.jus.br/home/files/publicacoes/artigos/0162008.pdf>. Acesso em: 18 de nov 2013.

RIO GRANDE DO SUL. Tribunal de Justiça do Rio Grande do Sul. Apelação Crime 70055372189, Rel. José Conrado Kurtz de Souza, sétima câmara criminal, julgado em 24/10/2013. Diário de Justiça eletrônico, Porto Alegre, RS, 31 out. 2013.

RIO GRANDE DO SUL. Tribunal de Justiça do Rio Grande do Sul. Apelação Crime 70052317104, Rel. Isabel de Borba Lucas, oitava câmara criminal, julgado em 16/10/2013. Diário de Justiça eletrônico, Porto Alegre, RS, 21 nov. 2013.

SILVA, João Carlos Carvalho da. Princípio da co-culpabilidade e sua implementação no ordenamento jurídico brasileiro. 2009. Disponível em: < http://mpto.mp.br/ cint/cesaf/arqs/040209043401.pdf>. Acesso em 18 nov. 2013. 
SILVA, Lucas Soares e; GIACOIA, Gilberto. Exclusão social e criminalização do excluído: uma reflexão sobre a seletividade do sistema penal brasileiro. In: SANTIAGO, Nestor Eduardo Araruna; BORGES, Paulo César Corrêa; PEREIRA, Cláudio José Langroiva. Direito Penal e Criminologia. In: CONGRESSO NACIONAL DO CONPEDI UFPB, 23., 2014. Anais eletrônicos... Florianópolis: FUNJAB, 2013, p. 432-456. Disponível em: $\quad<$ http://www.publicadireito.com.br/artigos/?cod=6d0893ce02e49265>. Acesso em: 01 jul. 2015.

ZAFFARONI, Eugenio Raul; PIERANGELI, José Henrique. Manual de direito penal brasileiro: parte geral - v. I. 7. ed. São Paulo: Revista dos Tribunais, 2009.

Recebido em: 29 de julbo de 2015 Aceito em: 19 de janeiro de 2016 